\title{
O Tempo Presente no Processo Teatral
}

\author{
Vera Lúcia G. Felício*
}

Resumo: Rejeitando a noção de um teatro burguês, comercial, sinônimo de recepção passiva, Peter Brook reflete sobre dois outros tipos de teatro que tentam responder à proposta de um teatro vivo: o "Teatro Sagrado" c o "Teatro Bruto". Ele se propòe a reabilitar o sentido do Sagrado e do Popular (Bruto) levando em conta as condições vigentes atuais e o contexto em que a prática teatral se efetiva. Palavras-chave: Teatro sagrado, teatro bruto, teatro imediato, ritual, vida.

Aqueles que se dedicam a refletir sobre a atividade teatral não podem fugir às questões fundamentais desta prática que remonta aos gregos da Antiguidade, concebida como "catarsis" na visão aristotélica, passando pelos "Autos" medievais, pela "Commedia dell' arte" com seu teatro itinerante, até chegar aos eventos teatrais contemporâneos que "explodem" o palco italiano, abolindo a quarta parede. Seja o "efeito de distanciamento" proposto por Brecht, seja o Teatro da Crueldade de Artaud, seja o Teatro Pobre de Jerzy Grotowski, para citar apenas alguns nomes, tidos como revolucionários, no âmbito da prática teatral, é, ainda e sempre, a mesma questão reavivada,

* Professora de Estética no Departamento de Filosofia da USP 
Felicio, V.L.G., discurso (19), 1992 : 43-58

embora delimitada e respondida de maneiras diferentes: qual é a necessidade da prática teatral? O que é um teatro vivo?

Como as respostas variam não apenas historicamente, num sentido diacrônico, mas também segundo os vários pensadores, no interior de um mesmo eixo sincrônico, preferimos centrar-nos na visão de Peter Brook, por ser um encenador teatral contemporâneo que, embora filiado ao pensamento de $\mathrm{Ar}$ taud, explicitamente, ainda considera Shakespeare imprescindivel para o teatro. Apesar de ter constituído com o "Royal Shakespeare Theater" um grupo denominado "Teatro da Crueldade", a fim de explorar as possibilidades de um Teatro Sagrado e Ritual, refere-se a Brecht, analogamente, como um dos maiores encenadores teatrais, para exemplificar o que denomina de "Teatro Bruto" ou "Popular", tão fundamental quanto o Teatro Sagrado, apesar de sua oposição.

Ora, o que unirá esses dois tipos de teatro, segundo P. Brook, é sua "necessidade". Ambos, em suas especificidades, tentam responder, por vias diversas, ao sentido do teatro e sua relação com a vida. E, apesar de opostos, há instantes breves e luminosos, em que estas duas visões teatrais se unem num mesmo espaço. É o raro momento em que ambos, num ato total, ultrapassam suas diferenças a fim de se constituirem num ato teatral vivo. $\dot{E}$ a partir deste pressuposto que P. Brook concebe o "Teatro Imediato". "É assim que compreendo um teatro necessário, um teatro onde entre atores e público existiria apenas uma diferença da situação e não uma diferença fundamental" (BROOK 1, p. 175).

Consideremos, inicialmente, o Teatro Sagrado e, em seguida, o Teatro Bruto, segundo P. Brook, mas, antes, passemos pelo Teatro Burguês (Deadly Theater), a fim de ressaltarmos a oposição de ambos enquanto teatros vivos a este Teatro Burguês "esclerosado".

Partindo do Teatro Burguês como uma forma teatral que designa um teatro estreitamente tradicional, convencional e comercial, P. Brook quer-nos alertar para o perigo de um espaço cênico esclerosado e sem vida. E, embora seja esta a forma teatral a mais frequente, ela mata o sentido do teatro, pois não tem como finalidade nenhuma pedagogia e nem mesmo visa à exaltação do público. E, por ser uma forma teatral repetitiva e monótona, não chega a divertir o espectador. O "sucesso" deste teatro cortesão provém da tentativa de 
equilibrio entre o tédio da repetição e a novidade; é necessário que o público se sinta seguro quanto ao conhecido, mas que, ao mesmo tempo, tenha a ilusão de uma certa dose de novidade. Este tipo de teatro se mantém graças a "sucessos" entediantes, mas, universalmente aceitos, porque reconhecidos. Em suma, o que P. Brook critica neste não-teatro porque é "mau-teatro", é seu odor de estagnação, não somente porque remete ao texto de uma autor já consagrado, esquecendo-se de lhe dar vida, detendo-se em fórmulas convencionais, mas porque se vende ao mercado e à estrutura econômica vigente, em detrimento de seu valor artístico. Teatro-mercadoria, cujo ritmo de produtividade segue o tempo da rapidez e da eficácia em termos de lucro.

O Teatro Burguês é um não-teatro na visão de P. Brook, isto é, sua denominação provém, antes, de uma caricatura do teatro vivo. Cabe-nos, então, redescobrir as qualidades intrínsecas do teatro e sua função vital. E é por esta via de exploração que surge o Teatro Sagrado como uma resposta possível a esta questão.

Ao se referir ao Teatro Sagrado, P. Brook nos diz: "Teria podido chamá-lo: o teatro do invisível - tornado - visível. Preferi a fórmula mais breve de 'Teatro Sagrado'. Que a cena seja um lugar onde o invisivel pode aparecer é uma idéia que tem uma intensa relevância sobre nosso espirito.” (BROOK 1, p. 65). O invisível aparece como uma necessidade que, apesar de se realizar através do Homem, atingir-nos-á, sem se reduzir ao mesmo. É comparável à música regida por um maestro que o público pode mistificar e cultuar, mas estando consciente de que não é ele que constitui a música, pelo contrário, é esta que o faz. A única exigência da música é que se esteja aberto e receptivo à mesma. Neste instante, diz-nos $\mathrm{P}$. Brook, o invisível tomará posse do regente musical. O denominado "teatro de evasão" não corresponde exatamente a um teatro inútil, pois, o teatro lírico, com suas cores, música e movimento, ainda que fosse considerado como evasão, instituia uma presença, comparável, segundo $\mathrm{P}$. Brook, à função da presença de um monge na cela de um prisioneiro.

O Teatro Sagrado, com sua sede de invisível e seu ritual, não é, portanto, simples evasão do cotidiano, mas, pelo contrário, surge enquanto crítica a um teatro desenraizado da vida. É esta a proposta de Artaud, bem como a de Jean Genet, embora por vias diversas. O teatro da dúvida, do mal-estar, da angústia 
e da lucidez passa a exigir o ritual cênico numa atmosfera hierática e mágica; magia e sonho, aspectos tão caros ao pensamento dos simbolistas. Este teatroritual, característico das civilizações orientais e que parece perdido ao olhar do ocidental, é o que estabelecia a relação entre arte e vida. Os ritos, com sua expressiva gestualidade, só podem ter função no teatro contemporâneo quando fazem do teatro uma experiência enriquecedora, gerando novas formas que transformam o espaço cênico, ampliando-o. Assim, P. Brook quer-nos mostrar que a experiência teatral é muito mais ampla do que uma sala com quatro paredes, cortina vermelha, um palco fixo acima da platéia com lugares hierarquicamente estabelecidos, onde uma história é narrada por um ou vários atores que cultuam o texto e o autor do mesmo, reproduzindo-o através de gestos e de fórmulas convencionais. Para P. Brook, mais do que teatro, há um ato teatral que nasce num espaço vazio que acolhe um ator enquanto alguém o observa, participando deste ato. Nesse sentido, a relação teatral exige sempre um ritual, se ele deseja ser vivo.

Contra a idéia de representação de um texto prévio, o Teatro Sagrado, através de sua gestualidade, enfatiza a encenação. E, assim como não há obra de arte que não exija percepção, pois, ou ela ainda é apenas um esboço, e, neste sentido, ainda não está terminada, ou, quando isolada e oculta do olhar do público, torna-se coisa e perece em seu valor estético. A obra depende deste olhar receptivo e aberto do público que a desvenda em seu mistério, é o enigma re-proposto a cada um de nós para ser revelada pelo olho que a percebe e a capta de modo válido e legitimo, sem, no entanto, esgotá-la jamais. Sua ambiguidade, em termos de mensagem estética, pede múltiplas leituras, que são respostas à obra enquanto esta aparece como um questionar contínuo àquele que a perscruta indefinidamente neste seu aparecer sob forma caleidoscópica e multifacetada. No Teatro Sagrado, o ritual cênico é a visualização sensível necessária que torna possível a linguagem do invisível. É assim que, antes de ser a simples reprodução de um texto prévio, o teatro, seja para Artaud, seja para P. Brook, é encenação. Sua expressividade não é anterior ou posterior à encenação, mas, coincide com a mesma. A encenação fala, torna-se linguagem.

O "erro" da visão teatral tradicional é o de acreditar que o texto pode nos ensinar o que foi escrito em negro sobre o branco, antes de refletir a propósito da maneira pela qual se the deu vida. A tradição e a erudição não bastam se não 
se apreender o sentido que é transmitido, e este não é simples repetição nem memória do passado. Imitar apenas as facetas exteriores da peça nada mais é do que perpetuar uma aparência ilegítima. É assim que, ao se referir a Shakespeare, P. Brook assinala-nos que o que está escrito são signos sobre o papel. As palavras de Shakespeare são transcrições das palavras que ele desejaria que disséssemos. O sentido exige que as palavras sejam consideradas em sua sonoridade, emitidas e pronunciadas por intérpretes que usam um certo timbre, um certo ritmo, onde as pausas ou o silêncio também falam e repercutem em nós. O sentido alia-se à musicalidade da linguagem; é isto a expressividade poética. Ora, este processo é deslanchado pelo dramaturgo e repetido pelo ator: "... a palavra é a pequena porção visivel de todo um universo oculto" (BROOK 1, p. 29).

O material de informação, livros, documentos, quadros, fotos... são apenas uma propedêutica ao sentido do texto, mas, de modo algum, esgotam-no. Analogamente, não se pode "explicar" a obra de um artista por fatores prévios à sua elaboração, quer sejam eles psicológicos ou sócio-econômicos, pois, embora possam contribuir para o esclarecimento da mesma, não dão conta de seu sentido do ponto de vista estético. Ninguém reduz ou explica, por exemplo, a pintura de Van Gogh por sua loucura, embora esta faça parte de sua arte. Suas telas não valem por sua loucura, embora esta se constitua como parte intrínseca de sua obra do ponto de vista da expressividade artística. É somente enquanto os aspectos da vida de um artista são relevantes para a sua obra, que estes possuem peso. É apenas neste sentido que arte e vida se entrelaçam, numa relação de simbiose entre ambas, jamais de causa-efeito. Uma peça clássica denominada "musical", "nobre", "heróica"... não possui significação absoluta. São conotações de linguagem, reflexos de uma atitude crítica própria a um determinado período. Consequentemente, tentar representar conforme estes cânones, é enveredar-se em direção a um teatro morto, ainda que sua pseudorespeitabilidade fizesse passá-lo por uma verdade absoluta.

O pensamento de P. Brook conduz-nos passo a passo para um teatro vivo, entendido como um processo: "Num teatro vivo, abordaríamos a cada dia o ensaio colocando à prova as descobertas da vigília, prestes a crer que a verdadeira peça nos escapa uma vez mais" (id., ibidem, p. 31). Esta é a diferença fundamental entre o teatro vivo e a visão tradicional que aborda os 
clássicos pressupondo que há um modelo prévio definido e um modo acabado de representar, convencional e imutável.

O Teatro Sagrado, ritual, só tem função quando um rito é perceptível pelo público, que se sente apto a vivê-lo. Como exemplo, o teatro de Jean Genet cria rituais de esterilidade e de degradação ou, ainda, Arrabal com sua conhecida peça $O$ cemitério de automóveis. Se o sagrado nos desertou, assim como o poético, o teatro ritual tenta resgatar no momento histórico contemporâneo um sagrado ligado à desintegração e à fragmentação de nossa época. Um Teatro Sagrado, como já o propusera Artaud (2), com o seu Teatro da Crueldade, no qual o centro ardente se exprimiria através das formas que lhe fossem mais próximas. Um teatro que teria como Duplo ou espelho a peste, pois agiria por contaminação, provocando o público, por analogia, numa atmosfera mágica em que o evento tomaria o lugar do texto escrito. A cena fala. É este deslocamento e ampliação da noção de texto que o Teatro Sagrado propõe. Além da linguagem articulada há uma linguagem da ação, dos sons, da palavra-paródia, da palavrainjúria, da palavra-choque e da palavra-grito. O poético vai além do literal.

O Teatro Sagrado exige uma exaustiva preparação corpóreo-gestual do ator. Este não declama simplesmente um texto prévio, mas, através do desbloqueamento das resistências musculares, visa adquirir uma desenvoltura dos movimentos corporais, a fim de obter uma expressividade significante em cena. Para comunicar a mensagem invisivel o ator descobre que são necessárias concentração e vontade, condições tão bem expressas na definição do ator, dada por Artaud: "um belo pesa-nervos (pèse-nerfs)". Essa exigência de preparo físico torna o ator consciente de que é necessário dispor de uma estrutura, pois não é suficiente sentir apaixonadamente. Há um esforço criador a fim de forjar uma nova forma, receptáculo e reflexo dos impulsos do ator. Por isso a linguagem é ação, expressa no ritual cênico. A magia está neste processo: a representação da idéia invisivel sob forma adequada, contagiando diretamente os que estão presentes ao evento.

Ao trabalhar com diferentes linguagens além da linguagem articulada, P. Brook serve-se de um evento, ou de um fragmento de experiência como materiais da criatividade teatral, exercitando-se com suas múltiplas possibilidades expressivas a fim de convertê-las em formas suscetiveis de serem partilhadas com o público. O ator não segue seus impulsos de modo cego, 
como um improvisador, aleatoriamente, mas é visto como um artista que deve procurar e escolher entre formas diferentes, a fim de que um grito ou um gesto sejam como um objeto descoberto e remodelado por ele. Foi das experiências com ritos tomados enquanto modelos repetitivos que P. Brook constatou que se expressa mais profundamente o sentido dos eventos do que através de seu desenvolvimento lógico-discursivo. A finalidade estava atingida: saber que o invisivel pode tornar-se visivel pela presença do executante. Analogamente à música que não se reduz a uma partitura escrita convencional e rigidamente, mas, para oferecer-se ao público necessita de um intérprete atento e receptivo à mesma, todo trabalho artístico pede, necessariamente, uma leitura cúmplice de seu sentido para vir a ser.

A linguagem das palavras é questionada em sua significação convencional imediata. $\mathrm{O}$ ator, ao falar, lança as palavras ao caos, numa dança frenética que transforma sua significação lógico-conceitual corrente. Como exemplo deste jogo com a linguagem P. Brook cita o Teatro do Absurdo, que se utiliza da linguagem de modo ilógico, introduzindo o ridículo na mesma e a extravagância no comportamento. As relações automáticas que o cotidiano estabelece na linguagem comunicativa sofre um curto-circuito. Todavia, este efeito de choque benéfico do Teatro do Absurdo não tardou a atenuar-se e isto não passa despercebido a P. Brook. Ele nota seu domínio muito limitado à epoca atual; a fantasia é superficial, as extravagâncias surrealistas não mais satisfariam Artaud, como não o satisfizera a estreiteza de uma peça de cunho psicologista. $\mathrm{O}$ projeto artaudiano, retomado por P. Brook e um grupo de atores totalmente devotados ao teatro, que criaria uma sucessão de cenas violentas, provocando explosões imediatas a emoções tão intensas que o teatro falado (de texto) seria dispensável, pede um público compativel ao mesmo. Um público que se desfizesse de todas as suas defesas, que quebrasse sua armadura e se deixasse penetrar, chocar e se violentar de tal modo que o teatro o preencheria com uma nova potência. Esta é a função viva do Teatro Sagrado na atualidade. Longe de ser identificado a uma contemplação passiva, o Sagrado vem ao encontro da força de libertação das garras opressivas do cotidiano.

Sem se ater a regras ou a receitas esclerosadas e esclerosantes, P. Brook retém a seguinte mensagem do Teatro da Crueldade, do visionário Antonin Artaud:" 'Teatro da Crueldade', a idéia de uma pesquisa oscilante (tâtonnante) 
em direção a um teatro mais violento, menos racional, mais extremo, menos verbal, mais perigoso. Há uma certa alegria nos choques violentos" (BROOK 1, p. 80). Todavia, se a idéia de choque é enfatizada por P.Brook, ele nos adverte para o perigo do "happening". Se, por um lado, este é rico em possibilidades ao destruir de um só golpe numerosas formas esclerosadas, ampliando o espaço teatral, alterando o ritmo da encenação, procurando atingir o público, se "nada é tabu" constitui-se como seu princípio, "nada é necessário" vem a ser o seu corolário. Neste sentido, um "happening" pode ser espontâneo, anárquico, cerimonioso... com o objetivo de despertar o público. Por outro lado, esta forma de pseudoliberdade contém e repete os mesmos símbolos obsessivos: da farinha às tortas, do vestir-se ao desnudar-se, lançar água, fazer contorsões no chão... acabam por se tornarem monótonos, anulando o efeito de choque visado. A "frénésie" dos choques acaba por conduzir o público a uma outra forma de passividade e ele volta a cair na apatia.

A aporia do happening, segundo P. Brook, está em se saber dosar a forma e a ausência de forma, a liberdade e a disciplina. É assim que compreender-se a visibilidade do invisivel é obra de uma vida toda. E é nisto que o Teatro Sagrado pode ajudar, pois não mostra apenas o invisivel, mas oferece condições que tornam possível sua percepção. Por isso, o Teatro Sagrado afasta-se do happening, pois, tal como este é praticado, o problema da percepção é rejeitado. Não basta participar do evento para se enriquecer a percepção. Há uma estruturação cênica precisa que é a finalidade do trabalho do encenador em conjunto com os atores, a fim de provocar o público, fazendo penetrar e animar o cotidiano pelo invisível. Era precisamente esta linguagem cênica hieroglífica, que une o concreto e o abstrato, o sensivel e o inteligivel, que Artaud denominava de "nova metafísica" ou "metafísica concreta", em oposição à metafísica tradicional que separa o inteligível e o sensivel, enfatizando o primeiro em detrimento do segundo. Ora, o Teatro Sagrado é a recuperação desta unidade dialética dos dois termos sem se esquecer de sua oposição, tornando visivel, através da linguagem cênica sensível, o invisível. O fundo e a força dionisíacos tomam forma pela encenação ritualística deste Teatro Sagrado que não adere a nenhuma instituição religiosa. O Sagrado toma, aqui, o sentido cósmico de união entre o ator e o público, de participação coletiva. Um exemplo marcante fornecido por P. Brook nos é dado pelos dançarinos de 
Merce Cunningham. Utilizam-se da disciplina adquirida para se tornarem mais conscientes das correntes sutis que passam num movimento. Tudo é espontâneo e, no entanto, tudo é ordenado. O silêncio irradia numerosas potencialidades, do caos à ordem, da confusão à estruturação. O invisível tornado visível é sagrado.

Um outro exemplo de teatro que deseja atingir o sagrado é o de Grotowski (3). Analogamente a um cerimonial, o teatro é uma possibilidade de cura, de saúde. O trabalho do ator é obra de uma vida, que elimina os obstáculos e as resistências ao seu autodesnudamento perante o público. O domínio técnico de seus meios físicos e psíquicos vai-lhe permitir abolir as barreiras, a fim de se "autopenetrar" pelo papel e de se exibir (pôr-se a nu para o outro). $\mathrm{O}$ ator não hesita em se mostrar tal como é. Atuar passa a ser um processo de abertura através do qual ele revela seus próprios segredos. É o que o faz ser um "ator santo", como se fosse uma oferenda ao espectador. O ator, como o sacerdote, na visão de Grotowski, realiza o rito por si e em nome dos demais. Na cerimômia que é o ato teatral, o ator elucida o que grita ao fundo de cada espectador e que está mascarado pela vida cotidiana. Esta é a sua finalidade sagrada de desvendamento.

$\mathrm{O}$ que une Grotowski, Cunningham e Beckett sob a denominação de Teatro Sagrado são os pequenos meios, um trabalho intenso, uma disciplina rigorosa, uma precisão absoluta em termos de linguagem cênica e sua destinação a um público pouco numeroso. Cada um deles, à sua maneira, respondeu à questão sobre a necessidade do teatro e sua relação com a vida.

Sagrado, pois, não é sinônimo de respeitoso porque longínquo, mas, de profundidade. E, à questão de P. Brook: onde procurarmos este Teatro Sagrado? "Nas estrelas ou sobre a terra?"Artaud já o dissera: na encenação.

Passemos ao Teatro Bruto ou Popular. É o teatro que sofre as intempéries do clima, feito sob o sol, com suor, que pode desprezar uma sala fechada, a fim de criar seu próprio espaço sobre tablados, nas praças, charretes... com um público que permanece sentado ou de pé, em torno de uma mesa ou numa praça. É, às vezes, o teatro dos salões dos fundos de um cabaré, dos subsolos, dos galpões, com apresentações únicas, ou, outras vezes, numa sala convencional de teatro. Esta é a principal riqueza do Teatro Bruto, aos olhos de P. Brook: ele está próximo das pessoas. Seja um teatro de marionetes, de sombras 
(nas aldeias gregas), o que caracteriza este tipo de teatro é a ausência de estilo. Através de condições precárias faz-se passar uma mensagem. O material é ilimitado, violando uma série de convenções. Este teatro termina por funcionar em termos de liberação social, posicionando-se, por sua própria estrutura, como anti-autoritário. Com sua sátira feroz e a caricatura grotesca ele produz o riso enquanto elemento crítico. O riso pelo riso parece-lhe inútil; ele só é legítimo quando faz crescer a energia do público, tornando-o mais lúcido. Se a alegria é o alimento do Teatro Bruto, não se deve esquecer de que a energia que produz rebelião e contestação, deve aí contribuir igualmente. P. Brook atrai nossa atenção para esta energia militante, que se confunde com uma energia criadora. Um dos melhores exemplos encontra-se no teatro brechtiano, com seu Teatro Épico. Em sua peça "Arturo Ui", esta energia poderia levar diretamente à guerra. $\mathrm{O}$ desejo de mudar de sociedade, de colocá-la face a face com sua hipocrisia possui um grande poder gerador de energia. A ação dos homens no Teatro Bruto é terra a terra, direta. O riso e a perversidade constituem-se como sua tônica.

$\mathrm{O}$ teatro brechtiano inicia-se como uma reação à concepção do naturalismo que dominava os teatros alemães na época, por um lado, e contra a ofensiva lírica do teatro total que visava arrebatar o espectador apenas pela emoção, por outro lado. Se havia um pouco de vida sobre a cena, em troca, os espectadores permaneciam passivos. Ora, isto não passou em branco para Brecht. Para este, um teatro necessário é o que não perde de vista a sociedade a serviço da qual ele está. Abole-se a quarta parede entre a sala e a cena e amplia-se a relação para cena-sala-mundo (social). O ator visa obter do público uma reação precisa. O "efeito de distanciamento" é um recurso utilizado por Brecht a fim de fazer uma pausa, interrompendo uma ação em sua significação ilusoriamente tida como "natural", a fim de, ao fazer este corte, esclarecer o público de que esta significação está enraizada historicamente e é passível de mudança. Sua necessidade atemporal é falsa; pelo contrário, ao fazer com que o público verifique novamente com um olhar critico o que se passa em cena, torna-o cada vez mais responsável pela sua práxis na sociedade. O teatro brechtiano provoca o espectador acionando sua razão a fim de avaliar os elementos de uma situação, levando-o a compreender melhor a sociedade na qual vive descobrindo que ela pode ser mudada. A paródia, a fábula, a música, 
a crítica irônica... são exemplos de recursos usados para realizar tal objetivo. O "efeito de distanciamento", com suas infinitas possibilidades, visa, incessantemente, a desmascarar a retórica dos atores. O próprio ator, ao praticar este método em relação a seu personagem, é capaz de julgar o valor de sua contribuição para uma elucidação crítica da sociedade.

Apesar desta função crítica discursivo-racional preponderante, o teatro brechtiano toma seu valor artístico das imagens cênicas que reclamam a adesão do público. Se a ilusão é criticável enquanto fim em si, ela é imprescindível para a linguagem cênica em sua função crítica. Para isso, Brecht opõe a ilusão morta à ilusão viva, a mensagem imprecisa à mensagem plena de vida; a forma fossilizada à sombra movente e a imagem estática à imagem móvel. A ilusão teatral é maléfica na medida em que conduz o espectador, evasiva e alienadamente, a um estado de transe hipnótico e de credulidade incondicional. Se, no entanto, a imagem cênica, portanto, ilusória enquanto representação, ligada ao "efeito de distanciamento", conduz ao corte, à ruptura e à crítica por parte do espectador, ela é necessária e legítima. Enquanto que a "má" ilusão pesa, a ilusão constituída de clarões e de impressões fugidias mantém desperta a acuidade da imaginação do espectador, durando, apenas, o momento necessário.

O teatro brechtiano, teatro em consonância com a luta revolucionária, com o canto dos trabalhadores e com as lendas populares, constitui-se, segundo P. Brook, num dos melhores exemplos do teatro militante. O "Berliner Ensemble" lançou um desafio: ser popular e ser revolucionário. Resta-nos ver como realizar essa proposta levando-se em conta as diferentes circunstâncias sócio-políticas de hoje.

Se o Teatro Bruto e o Teatro Sagrado são opostos e discordantes, ambos constituem-se como respostas à necessidade do ato teatral enquanto força viva. Se ambos são o outro da sociedade porque esta deve ser a maneira pela qual a força do teatro se manifesta nas circunstâncias históricas do século XX, não nos esqueçamos de que o teatro do século XVI entrelaçava os três níveis: os deuses, a corte e o povo, embora fossem distintos. A liberdade de movimento no teatro elisabetano assenta-se no pressuposto de que o autor podia não apenas percorrer o mundo, mas passar livremente do mundo da ação ao mundo das impressões interiores. Graças às metáforas das imagens extraidas do mundo 
exterior, Shakespeare dava vida à existência psíquica. Sua força teatral foi a de representar o homem sob todos os seus aspectos. Se o espectador se identificava emocional e subjetivamente às situações e aos personagens, ao mesmo tempo julgava a sociedade circundante, politicamente. Mais do que uma simples sucessão de eventos, P. Brook convida-nos, em sua leitura de Shakespeare, a considerar uma peça deste último enquanto um conjunto de formas e de sentidos, análogo a um caleidoscópio de várias faces, onde o fio da história é apenas um dos numerosos aspectos e que não deve ser estudado separadamente. Para tal abordagem P. Brook propõe-nos abordar "Rei Lear" não como uma narração linear, mas como um "nó de inter-relações". Por esta via, recuperar-se-á a atualidade de Shakespeare; a peça entrará em relação direta com os temas contemporâneos: o antigo e o novo em nossa sociedade, nossas artes, nossa forma de viver, ... a significação existirá no instante do espetáculo.

$\mathrm{O}$ convite de P. Brook é para percebermos a beleza teatral porque estamos convencidos de sua necessidade. Se não identificarmos o Teatro Sagrado à bruxaria, se não confundirmos o Teatro Bruto ou popular com baixo nível artístico, se nos despregarmos de receitas e de fórmulas artaudianas e brechtianas, a fim de captarmos seu sentido teatral mais profundo, estaremos aptos a recuperar a necessidade teatral, na medida em que chegarmos à concepção do teatro como uma revolução perpétua. É o ideal do Teatro Imediato tal como nos propõe P. Brook, através da expressiva metáfora: "O teatro não é um lugar como os outros. Ele é como uma lupa que aumenta a imagem, mas também como uma lente de óptica, que a reduz. E um pequeno universo, que corre o risco de estreitar-se ainda mais... O teatro retrai a vida" (BROOK 1, p. 133). Por ser diferente da vida cotidiana ele corre o perigo de ser cortado da mesma. Mas, no teatro, uma questão prática é sempre uma questão artística e, vice-versa, a estética é uma questão prática. Todo elemento cênico tem um peso e uma legitimidade; o simples deslocar de um objeto muda o sentido da peça. O encenador vive segundo regras precisas, partilhadas por todos, embora, tácitas. É por isso que o teatro se afirma sempre no presente, ao contrário do tempo pretérito cinematográfico. Na concepção de P. Brook, "O teatro é a arena onde pode ter lugar um confronto vivo. A concentração de um grande número de pessoas carrega em si uma intensidade excepcional" (id., ibidem, p. 135). 
O Teatro Imediato significa a experiência teatral de P. Brook. Não há regras nem receitas previamente fixadas. Só se aprende trabalhando, com a ajuda de um encenador e, até, de um crítico. A atividade teatral é a relação estabelecida entre o ator, a peça e o público; durante os ensaios, a relação se dá entre o ator, a peça e o encenador. Ao se trabalhar sobre a cena, esta fornecerá sua estruturação e seu ritmo, dando o critério às formas teatrais mais convenientes ao texto, se houver, ou ao itinerário ou roteiro. Há um trabalho do decorador que caminha passo a passo com o do encenador, pacientemente mudando ou eliminando detalhes, até que a concepção da peça tome forma. A criatividade teatral é um longo processo. Há um projeto claro, inicialmente, sem ser rigido, "aberto" e não "fechado". Diferentemente do pintor de cavalete que dispõe de duas dimensões, o encenador dispõenão da imagem de uma cena, mas, da imagem de uma cena em movimento; o tempo é sua quarta dimensão.

Esse trabalho experimental que é essencialmente teatral obriga encenadores, atores e decoradores a se recolocarem a questão da linguagem cênica e de sua estruturação, como se fosse a primeira vez. Os ensaios são um processo de maturação da expressividade cênica. Há um tempo certo para tudo; reconhecer esses momentos é a arte do encenador. O ator teatral é resultado de uma reflexão, isto é , comparações, meditações, erros, hesitações e recomeços. E se o pintor de cavalete, por exemplo, também passa por èsse processo, é em segredo; o encenador revela suas incertezas aos atores e, em troca, dispõe de um material (o ator) que reage e evolui. Os atores, material vivo, falam, sentem e exploram constantemente as possibilidades teatrais. Assim, "Ensaiar uma peça, é pensar em voz alta e diante de todos" (BROOK 1, p. 145). A figura do encenador está ai para atacar e render-se, para provocar e se retirar, até que a indefinível estruturação da peça seja elucidada. Deve sentir onde o ator deseja ir e o que ele quer evitar, compreendendo que obstáculos se erguem diante de suas próprias intenções. A função do encenador é a de ajudar o ator a se arrancar as máscaras.

Do lado do ator, por ser este um instrumento mais sensivel, nele a vibração pode ser apreendida. A ele se pede uma disponibilidade total que não somente se identifica ao talento, mas requer trabalho. A idéia lançada pelo encenador penetra no ator como um "ato de possessão". Dai o trabalho do encenador, tal como Grotowski já o propusera, ser o de ajudar o ator a se desembaraçar de idéias preconcebidas, mecanizadas em gestos repetitivos, que ocultariam signi- 
ficações mais profundas; é um trabalho "negativo". Ser ator requer um profundo trabalho de libertação do convencional e do estereótipo, a fim de poder descobrir o que há de específico em si próprio; somente assim seu gesto será criativo. Mas, com este autodesnudamento, P. Brook não deseja encerrar o ator no mais extremo individualismo, pelo contrário, o Teatro Imediato pede que a criação seja coletiva. Um ato criador poderá ser desfeito se o olhar de um outro lhe fornecer elementos mais sólidos que o façam reformular o esboço inicial. Assim, o ator deve destruir e abandonar todos os resultados que obteve, ainda que isto que ele encontre não lhe pareça muito diferente do primeiro. Artaudianamente P. Brook mostra-nos que, se o papel fabricado pelo ator parece ser sempre o mesmo, a cada noite, é por miopia e insensibilidade do próprio ator, pois, assim como "a cena do Teatro da Crueldade não se repete", assim também o papel que foi realmente criado, para continuar semelhante a si mesmo, deve ser recriado incessantemente, o que o torna sempre diferente. O teatro é um processo ancorado num ritual em que a metáfora é signo e ilustração, isto é, um fragmento de linguagem. Cada entonação e cada estrutura rítmica correspondem a uma experiência diferente. A conotação promove o sentido da peça. O significado está intimamente correlacionado à materialidade do significante cênico, num corpo-a-corpo indestrutivel, de modo que, se alterarmos um deles, o outro sofrerá consequências.

Apesar das diferentes formas teatrais, o que todos os teatros possuem em comum é a necessidade de um público, pois, segundo P. Brook, é o público o termo final das etapas da criação. Ainda que a participação ativa do público possa ser invisivel, ela é indivisivel do ato teatral. Ora, não é esta concepção, precisamente, que se encontra no âmago do Teatro Pobre de Grotowski, isto é, o teatro como "relação fundamental entre ator-espectador"? Por isso o teatro é, no fundo, sempre o tempo presente, do "aqui e agora". Além de seduzir o público, é necessário que o teatro crie no mesmo uma "fome" e uma "sede" intensas. É o "apetite de vida" em termos de Artaud. Numa época em que tudo se transforma, a pesquisa é uma pesquisa de forma. Destruir antigas formas e tentar novas, diz-nos P. Brook. Encontrar novas palavras, novas relações, novos espaços e novas temporalidades. Não se chegou, ainda, a um estilo universal, como nos teatros e óperas do século XIX. Todavia, não há apenas destruição e mudanças; há certezas nos momentos em que se realiza uma 
experiência total, porque coletiva, e que P. Brook denomina Teatro Total. Este teatro é o que concerne à peça e ao espectador, entrelaçando-os, não havendo mais necessidade das divisões entre Teatro Burguês, Teatro Sagrado e Teatro Bruto. Há, neste instante, apenas o Teatro da alegria, da celebração e do sentido partilhado que são aspectos do teatro vivo. Todavia, uma vez que este clarão efêmero do teatro vivo eclode, não há imitação que possa recuperá-lo, sem cair na servidão. É aí que a pesquisa deve recomeçar para se fugir da morte. $\mathrm{O}$ ato teatral é uma libertação, embora, fugaz. Se se fala em representação teatral, isto não significa uma imitação ou descrição de um evento passado, mas é a abolição entre o ontem e o hoje. A representação, segundo P. Brook, é uma colocação no presente, favorecendo um retorno à vida. $\mathrm{O}$ Teatro Imediato é aquele que traça um gesto real no imediato, porque a ação teatral é viva. Passa-se da repetição à representação, isto é, não se isola mais o ator da platéia, nem o espetáculo do público. O Teatro Imediato engloba-os. O público sofreu uma mudança na medida em que abandonou a vida cotidiana repetitiva em função de uma "arena", onde cada momento é vivido mais clara e mais intensamente. Se o público assiste ao espetáculo, o ator assiste ao público.

Eis os três elementos indispensáveis ao evento teatral vivo, na concepção de P. Brook: repetição, representação e assistência, sem jamais se esquecer de que toda verdade em teatro é sempre um processo, porque o ato teatral é sempre um recomeçar. Atualmente, um teatro vital e necessário não pode evitar estar em desarmomia com a sociedade, contestando os valores estabelecidos, em lugar de celebrá-los. O papel do artista, neste teatro, é o de provocar as reações do público, na medida em que este mesmo público está decidido a se questionar; e só pode haver celebração comum enquanto o artista é o porta-voz de um público, enquanto este é capaz de celebrar o rito teatral, dionisiacamente.

$\mathrm{O}$ Teatro Imediato, embora cante o efềmero, não celebra a moda. $\mathrm{O}$ instrumento do teatro é o sangue e a carne do ator; os meios sensiveis e a mensagem não se separam do espaço vazio que é o teatro, pedindo o olhar receptivo, embora não passivo, do público que participa de seu ritual vivo.

À questão novamente recolocada: o que é teatro? P. Brook nos responde: "O teatro é uma arte autodestrutiva. Ele é escrito sobre a areia” (BROOK 1, p. 32). 
Abstract: Rejecting the notion of bourgeois, commercial theater, synonymous of passive reception, Peter Brook reflects about two other types of theater that have responded to the proposal of a living theater: the "Sacred Theater" and the "Brutish theater". He attempts to rescue the meaning of the Sacred and the Popular (The Brutish), taking into account, the actual standing conditions and the context in which the theatrical practice happens.

Key-words: sacred theater, brutish theater, immediate theater, living theater, ritual, life.

\section{Bibliografia}

1. BROOK, Peter. L'Espace Vide: Écrits sur le théatre. Paris, Ed. du Seuil, 1972.

2. ARTAUD, Antonin. Le Théâtre et son Double, Oeuvres Complètes. Paris, Gallimard, tomo IV.

3. GROTOWSKI, Jerzy. Para um Teatro Pobre. Tradução de Rosa Macedo e J.A. Osório Mateus. Forja, Ed. L'Âge d'Homme S.A, 1975. 